\title{
The underactive bladder: detection and diagnosis [version 1;
}

\section{peer review: 2 approved]}

\author{
Nadir Osman, Altaf Mangera, Christopher Hillary, Richard D. Inman (iD, \\ Christopher R. Chapple
}

Department of Urology, Sheffield Teaching Hospitals NHS Trust, Sheffield, UK

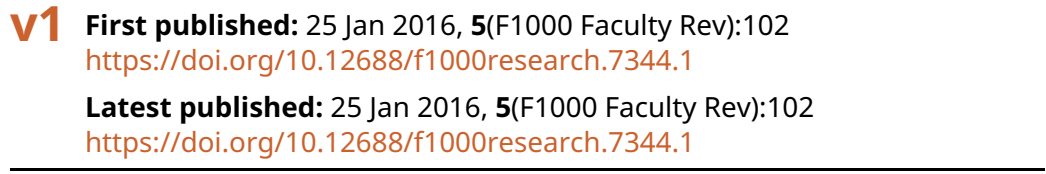

\section{Abstract}

The inability to generate a voiding contraction sufficient to allow efficient bladder emptying within a reasonable time frame is a common problem seen in urological practice. Typically, the symptoms that arise are voiding symptoms, such as weak and slow urinary flow. These symptoms can cause considerable bother to patients and impact upon quality of life. The urodynamic finding of inadequate detrusor contraction has been termed detrusor underactivity (DUA). Although a definition is available for this entity, there are no widely accepted diagnostic criteria. Drawing parallels to detrusor overactivity and the overactive bladder, the symptoms arising from DUA have been referred to as the "underactive bladder" (UAB), while attempts to crystallize the definition of UAB are now ongoing. In this article, we review the contemporary literature pertaining to the epidemiology and etiopathogenesis of DUA as well as discuss the definitional aspects that are currently under consideration.

Keywords

Underactive bladder, detrusor underactivity, chronic urinary retention

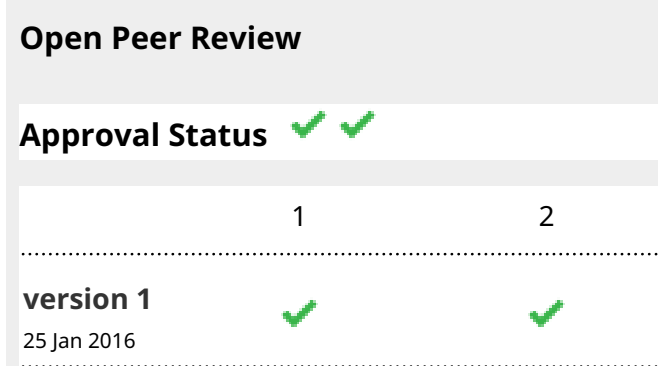

1. Naoki Yoshimura, University of Pittsburgh, Pittsburgh, USA

2. Peter F.W.M Rosier ID, University Medical Center Utrecht, Utrecht, The Netherlands Any comments on the article can be found at the end of the article.

\section{Corresponding author: Nadir Osman (nadirosman@hotmail.com) \\ Competing interests: The authors declare that they have no competing interests.}

Grant information: Nadir Osman has received a grant from Astellas. Christopher R. Chapple has received grants and personal fees from Astellas, Allergan, and Recordati. All the other authors have no conflicts of interest to declare.

Copyright: @ 2016 Osman $\mathrm{N}$ et al. This is an open access article distributed under the terms of the Creative Commons Attribution License, which permits unrestricted use, distribution, and reproduction in any medium, provided the original work is properly cited.

How to cite this article: Osman N, Mangera A, Hillary C et al. The underactive bladder: detection and diagnosis [version 1; peer review: 2 approved] F1000Research 2016, 5(F1000 Faculty Rev):102 https://doi.org/10.12688/f1000research.7344.1

First published: 25 Jan 2016, 5(F1000 Faculty Rev):102 https://doi.org/10.12688/f1000research.7344.1 


\section{Introduction}

Detrusor underactivity (DUA) is a common bladder dysfunction observed in both men and women undergoing urodynamic studies for the assessment of lower urinary tract symptoms (LUTS). It is typically associated with voiding LUTS such as slow urinary flow and intermittency but may also result in storage and postmicturition LUTS. Despite being commonly encountered in routine clinical practice, DUA has been given relatively little attention in clinical and scientific research. Not only can DUA arise in bothersome symptoms but its occurrence may impact upon the outcome of treatments for other dysfunctions, such as bladder outlet obstruction and stress urinary incontinence. Recently, there has been renewed interest in DUA, the associated symptoms, and potential treatments. This article aims to review the recent literature regarding the epidemiology, etiopathogenesis, and diagnosis of DUA and its associated symptoms.

\section{Definition}

A plethora of terms have been used to describe a bladder that does not contract efficiently. Terms such as detrusor areflexia, hypotonic bladder, atonic bladder, detrusor failure, impaired detrusor contractility, and chronic retention all reflect the lack of consensus and uncertainty as to the pathophysiological mechanisms at play. In an effort to standardize terminology, the International Continence Society report in 2002 used the term DUA to describe a urodynamic abnormality. This was defined as "a contraction of reduced strength and/or duration, resulting in prolonged bladder emptying and/or failure to achieve complete bladder emptying within a normal time span"1. This definition is necessarily vague on specifying the parameters for length and strength of contraction and prolonged voiding, as what is normal has not yet been established.

\section{Signs and symptoms}

There is a lack of prospective studies correlating DUA and its associated clinical signs and symptoms. In clinical practice, the typical presentation is of voiding LUTS such as reduced flow, prolonged flow, hesitancy, and intermittency. After voiding, some patients may report a sensation of incomplete bladder emptying, which may be related to a raised post-voiding residual (PVR).

One could speculate that the presence of storage symptoms is related to the bladder sensory function in the individual patient, such that patients with poor or absent bladder sensation will have a reduced urge to pass urine, which will result in infrequent voiding. Anecdotally, some patients may report they lack any perception of their bladder emptying during the voiding process. Should these patients retain a large enough PVR, they may also experience incontinence, particularly during the night. This clinical picture is commonly termed chronic urinary retention (CUR). Patients with retained bladder sensation may void with a normal frequency pattern or have increased frequency, nocturia, and incontinence should the PVR be high enough.

There has been some debate about whether a symptom complex is associated with DUA, referred to by some as the underactive bladder (UAB), which is rather analogous to detrusor overactivity (DO) and the overactive bladder (OAB) symptom complex. This is certainly an attractive concept, as it could, in theory, allow patients to be diagnosed and treated on the basis of symptomatology. Nevertheless, there are clear difficulties in defining a specific set of symptoms that do not overlap significantly with LUTS due to benign prostatic enlargement (BPE). Clearly in women this is less likely to be problematic given the relatively rare occurrence of obstructive causes. A working definition for $\mathrm{UAB}$ was recently proposed by an expert consensus group: “...a symptom complex suggestive of detrusor underactivity and is usually characterised by prolonged urination time with or without a sensation of incomplete bladder emptying, usually with hesitancy, reduced sensation on filling, and a slow stream"2.

\section{Epidemiology}

Given the inability to diagnose DUA without an invasive urodynamic study, it is unsurprising that there is little information on its prevalence on a population basis. There is no single non-invasive proxy measure (e.g. raised PVR, reduced urinary flow rate) that could reliably identify patients with the condition. Clinical series of patients with LUTS undergoing urodynamic studies offer the best available evidence as to the prevalence of DUA. In younger men ( $<50$ years), prevalence is $9-28 \%$, which rises to $48 \%$ in elderly men $(>70 \text { years })^{3}$. In elderly women, prevalence rates are between 12 and $45 \%$ and peak in the institutionalized elderly. Older frail patients often have co-existent DO, and this entity was originally described by Resnick and co-workers in 1987 as detrusor hyperactivity impaired contractility (DHIC) ${ }^{4}$.

\section{Etiopathogenesis}

Given the diverse patient groups who can be affected by DUA, it is clear that the etiopathogenesis is likely to be multi-factorial. There seems to be an assumption in the literature that aging leads to a decline in detrusor contractile function. While plausible, it must be emphasized that there is no conclusive evidence that this is the case. The available data from animal and human studies is often quite contradictory.

The etiological factors resulting in DUA can be broadly classified as neurogenic or myogenic.

\section{Myogenic factors}

Any pathological process that changes the normal structure and/or functioning of the extracellular matrix or the myocytes of the detrusor may cause a loss in the generation or transmission of a contraction. Factors that may affect the contractile activity of the myocytes include disruption of important cellular mechanisms (e.g. ion storage/exchange, excitation-contraction coupling, calcium storage, and energy generation). The implication of this is that even if efferent neuronal activity is normal, an impaired contraction will result ${ }^{5}$.

Supporting the idea that myogenic factors may be important, morphological changes have been observed within both the normally aged and the diseased detrusor. Much of this work was conducted by Elbadawi, who suggested that specific ultrastructural features detected by electron microscopy were associated with aging and different bladder dysfunctions including DUA ${ }^{6-8}$. The specific pattern associated with DUA was described as the "degeneration" pattern, characterized by widespread disrupted myocytes with axonal 
degeneration ${ }^{6}$. What is not clear is whether detrusor myocyte disruption is in itself the cause of DUA or the result of an underlying pathological process.

\section{Neurogenic factors}

Intact bladder sensation is central to the voiding reflex. The afferent nerves monitor bladder volume during the storage phase and also during the voiding phase. Afferent nerves arising at the level of the urethra may also have a contributory role in perceiving flow through the urethra ${ }^{9,10}$. If afferent functioning is reduced, this may lead to a reduction in the strength or premature termination of the voiding reflex ${ }^{11}$.

\section{Bladder outlet obstruction}

It has long been held that DUA occurs as a secondary effect of prolonged bladder outlet obstruction (BOO). This assumption has been largely derived from work in animals, particularly the rodent, where partial $\mathrm{BOO}$ is induced by a constricting metal ring or ligature. The process by which DUA occurs has been widely described and includes three phases ${ }^{12,13}$ :

1. Following obstruction, there is increased bladder outlet resistance leading to bladder wall distension

2. Compensatory hypertrophy and hyperplasia of the detrusor then occurs associated with a rise in tissue blood supply

3. Initially, contractile function is maintained; however, after a variable period of time, contractility is dissipated with a reduction in bladder emptying ability (decompensation)

Relating the insights from this work to humans is problematic, as the animals studied are usually young and female with an acute obstruction induced using a constricting ring. This is unlikely to be a good representation of the common clinical scenario of an elderly man with compressive benign prostatic obstruction. Interestingly, the largest longitudinal study available has shown that in man, prolonged BOO does not usually result in decompensation and DUA. In a group of 170 men with $\mathrm{BOO}$ demonstrated on pressure-flow studies, no significant deterioration in urodynamic parameters was observed at a mean follow up of 13.9 years (no change in pdet@Qmax [detrusor pressure at maximum flow] and a reduction in Qmax [maximum flow rate] of only $1 \mathrm{ml} / \mathrm{s})^{14}$.

\section{Diabetes mellitus}

Diabetic bladder dysfunction (DBD) (or diabetic cystopathy) is a well-recognized cause of DUA. Diabetes mellitus probably affects function through both a myogenic and a neurogenic mechanism leading to a decline in bladder emptying ability throughout the course of the disease $\mathrm{e}^{15,16}$. It is traditionally thought that this predominately occurs through hyperglycemia-induced axonal degeneration and segmental demyelination leading to impaired afferent and efferent bladder function (autonomic neuropathy) $)^{17}$. Myogenic mechanisms are less clearly elucidated, though it is likely that changes in intercellular connections and excitability, intracellular signaling, and receptor density and distribution are implicated ${ }^{18}$.

\section{Diagnostic aspects}

Currently, the only accepted modality for diagnosing DUA is an invasive pressure-flow test (or urodynamic study). However, there are no widely accepted criteria for diagnosing DUA. Most proposed methods relate to the measurement of the strength of the detrusor contraction.

\section{Detrusor contraction strength}

A detrusor contraction generates pressure and flow ${ }^{19}$; therefore, many authors have used two measurements to approximate contraction strength and thereby diagnose DUA: the maximal flow (Qmax) and the detrusor pressure at maximal flow (Pdet@Qmax). Most often a reduction in either is considered to be lower than the "normal" range. Historically, for men the normal ranges are derived from a series of men undergoing de-obstructive surgery ${ }^{20,21}$. In other groups, such as healthy men and women, in particular, the ranges are less well established ${ }^{22-24}$. Although relatively simple to apply, this method has two flaws. Firstly, it is likely to be an inaccurate method of determining the maximal pressure generated by the bladder due to the bladder outlet relation (BOR), the normal inverse correlation between detrusor pressure and urine flow during voiding ${ }^{25}$. Essentially, the BOR can be summed up as during voiding the pressure is highest when flow is lowest and vice versa, hence the pdet@Qmax represents the point of lowest bladder pressure during voiding. Secondly, the fact that the flow rate is also impacted upon by the degree of bladder outlet resistance is not considered. This is important because when detrusor pressure is low, the cause of low flow may also have its basis in obstruction (e.g. due to BPE) or alternatively a normal Qmax can result from reduced outlet resistance even if detrusor pressure is low (e.g. post-prostatectomy incontinence).

In order to gain a more accurate assessment of contraction strength, different methods of measuring isovolumetric bladder pressure have been introduced:

\section{Watts factor}

This is an estimate of the power per unit area of the bladder surface that is generated by the detrusor. The formula for calculation is $W F=[(p d e t+a)(v d e t+b)-a b] / 2 \pi$ where vdet is detrusor shortening velocity and $\mathrm{a}$ and $\mathrm{b}$ are fixed constants $\left(\mathrm{a}=25 \mathrm{cmH}_{2} \mathrm{O}\right.$, $\mathrm{b}=6 \mathrm{~mm} / \mathrm{s}$ ) derived from experimental and clinical data ${ }^{26}$. The main pros of the WF are that it is not dependent on bladder volume ${ }^{26}$ and is not influenced by increased outlet resistance ${ }^{27}$. There are, however, no validated values for what is considered normal. Currently, the WF is little used in practice due to its complexity as well as the fact that it assesses only strength of contraction, rather than duration.

\section{Projected isovolumetric pressure (PIP)}

The PIP was proposed by Schäfer, who used a straight line to represent the BOR and then "projected" back to the y-axis (pdet) from the point representing pdet@Qmax to obtain the isovolumetric pressure. This projection is calculated by the formula PIP=Pdet@ $Q \max +K Q \max$ where $\mathrm{K}$ is a fixed constant representing the steepness of the angle of the BOR to $\mathrm{x}-\mathrm{a}$ axis $^{28} . \mathrm{K}$ is dependent on the specific population studied and differs between men and women ${ }^{29}$; in men it is usually taken as 5. The suggested groupings for PIP are as follows:

- >150 - strong contractility

- 100 to 150 - normal contractility

- 50 to 100 - weak contractility

- $<50$ - very weak contractility 
There are two other reported variants of the PIP: the detrusor coefficient (DECO), which is the PIP divided by 100, and the bladder contractility index (BCI), which is essentially the same as PIP but with different groupings. The main advantage with these formulae is that they are easy and quick to use; however, they may overestimate PIP and have less test-retest reliability than measuring isovolumetric pressures directly ${ }^{30}$.

\section{Mechanical occlusion of flow}

This entails the direct measurement of isovolumetric pressure by the mechanical obstruction of urine flow $^{31}$. There are two methods for this measurement: (1) a stop test, the interruption of flow once it has already started, or (2) continuous occlusion test, where urine flow is impeded before and throughout the duration of the detrusor contraction. Stop tests can be voluntarily induced by the patient by contraction of the rhabdosphincter or alternatively the urodynamicist can impede flow through methods such as manual occlusion of the urethra. The voluntary stop test tends to underestimate pressure by about $20 \mathrm{cmH}_{2} \mathrm{O}$, which is likely to be attributable to a reflex detrusor inhibition brought on by sphincter contraction ${ }^{30,32}$. The voluntary test may not be possible in patients with sphincter weakness and in the elderly, whereas continuous occlusion can be painful and does not provide the opportunity for synchronous flow measurement.

\section{Detrusor contraction speed}

If a bladder is slow to contract, then this could also potentially result in DUA. Cucchi and co-workers proposed the parameter of detrusor shortening velocity, as calculated by the formula vdet $=$ $\mathrm{Q} / 2[3 /(\mathrm{V}+\mathrm{Vt}) / 4 \pi]^{0.66}$ where $\mathrm{Q}$ represents the flow rate $(\mathrm{ml} / \mathrm{s})$, $\mathrm{V}$ represents bladder volume $(\mathrm{ml})$, and $\mathrm{Vt}$ represents the volume of non-contracting bladder wall tissue. They found that a reduction in shortening velocity was evident before a decline in Watt factor in both men $^{33,34}$ and women ${ }^{35}$.

\section{Ambulatory urodynamics}

It is not uncommon for a patient to be unable to void during a urodynamic study due to anxiety; this has been termed "bashful bladder", which has been attributed to inadequate relaxation of the rhabdosphincter combined with reflex detrusor inhibition. This situation is usually identified by taking a good clinical history of previous voiding symptoms; however, if doubt persists, then an ambulatory urodynamic study may be helpful ${ }^{36,37}$.

\section{Conclusions}

DUA remains a poorly characterized and poorly understood bladder dysfunction. Its clinical correlate, UAB, has recently been introduced into clinical usage, yet it remains unclearly defined. To progress the current situation, there is a need to investigate the common mechanisms by which patients develop DUA as well as to collect prospective data that can be used to correlate the symptoms and signs with an underlying urodynamic abnormality.

\section{Competing interests}

The authors declare that they have no competing interests.

\section{Grant information}

Nadir Osman has received a grant from Astellas. Christopher R. Chapple has received grants and personal fees from Astellas, Allergan, and Recordati. All the other authors have no conflicts of interest to declare.
1. Abrams P, Cardozo L, Fall M, et al.: The standardisation of terminology of lowe urinary tract function: report from the Standardisation Sub-committee of the International Continence Society. Neurourol Urodyn. 2002; 21(2): 167-78. PubMed Abstract | Publisher Full Text

2. Chapple $\mathrm{CR}$, Osman $\mathrm{NI}$, Birder L, et al.: The underactive bladder: a new clinical concept? Eur Urol. 2015; 68(3): 351-3. PubMed Abstract | Publisher Full Text

3. F Osman NI, Chapple CR, Abrams $\mathrm{P}$, et al.: Detrusor underactivity and the underactive bladder: a new clinical entity? A review of current terminology, definitions, epidemiology, aetiology, and diagnosis. Eur Urol. 2014; 65(2): 389-98. PubMed Abstract | Publisher Full Text | F1000 Recommendation

4. $\quad F$ Resnick NM, Yalla SV, Laurino E: The pathophysiology of urinary incontinence among institutionalized elderly persons. N Engl J Med. 1989; 320(1): 1-7.

PubMed Abstract | Publisher Full Text | F1000 Recommendation

5. F Brierly RD, Hindley RG, McLarty E, et al:: A prospective controlled quantitative study of ultrastructural changes in the underactive detrusor. J Urol. 2003; 169(4): 1374-8.

PubMed Abstract | Publisher Full Text | F1000 Recommendation

6. Elbadawi A, Yalla SV, Resnick NM: Structural basis of geriatric voiding dysfunction. Il. Aging detrusor: normal versus impaired contractility. $J$ Urol. 1993; 150(5 Pt 2): 1657-67.

PubMed Abstract

7. Elbadawi A, Yalla SV, Resnick NM: Structural basis of geriatric voiding dysfunction. III. Detrusor overactivity. J Urol. 1993; 150(5 Pt 2): 1668-80. PubMed Abstract
8. Elbadawi A, Yalla SV, Resnick NM: Structural basis of geriatric voiding dysfunction. IV. Bladder outlet obstruction. J Urol. 1993; 150(5 Pt 2): 1681-95. PubMed Abstract

9. Feber JL, van Asselt E, van Mastrigt R: Neurophysiological modeling of voiding in rats: urethral nerve response to urethral pressure and flow. Am J Physiol. 1998; 274(5 Pt 2): R1473-81. PubMed Abstract

10. F Bump RC: The urethrodetrusor facilitative reflex in women: results of urethral perfusion studies. Am J Obstet Gynecol. 2000; 182(4): 794-802; discussion 802-4.

PubMed Abstract | Publisher Full Text | F1000 Recommendation

11. Suskind AM, Smith PP: A new look at detrusor underactivity: impaired contractility versus afferent dysfunction. Curr Urol Rep. 2009; 10(5): 347-51. PubMed Abstract | Publisher Full Text

12. Levin RM, Longhurst PA, Barasha B, et al:: Studies on experimental bladder outlet obstruction in the cat: long-term functional effects. $J$ Urol. 1992; 148(3): 939-43.

PubMed Abstract

13. Saito M, Yokoi K, Ohmura M, et al: Effects of partial outflow obstruction on bladder contractility and blood flow to the detrusor: comparison between mild and severe obstruction. Urol Int. 1997; 59(4): 226-30. PubMed Abstract | Publisher Full Text

14. F Thomas AW, Cannon A, Bartlett $\mathrm{E}$, et al:: The natural history of lower urinary tract dysfunction in men: minimum 10-year urodynamic follow-up of untreated bladder outlet obstruction. BJU Int. 2005; 96(9): 1301-6. PubMed Abstract | Publisher Full Text | F1000 Recommendation 
15. F Lifford KL, Curhan GC, Hu FB, et al.: Type 2 diabetes mellitus and risk of developing urinary incontinence. J Am Geriatr Soc. 2005; 53(11): 1851-7. PubMed Abstract | Publisher Full Text | F1000 Recommendation

16. F Lee WC, Wu HP, Tai TY, et al.: Effects of diabetes on female voiding behavior. J Urol. 2004; 172(3): 989-92. PubMed Abstract | Publisher Full Text | F1000 Recommendation

17. Hill SR, Fayyad AM, Jones GR: Diabetes mellitus and female lower urinary tract symptoms: a review. Neurourol Urodyn. 2008; 27(5): 362-7. PubMed Abstract | Publisher Full Text

18. Daneshgari F, Liu G, Birder L, et al.: Diabetic bladder dysfunction: current translational knowledge. J Urol. 2009; 182(6 Suppl): S18-26. PubMed Abstract | Publisher Full Text | Free Full Text

19. Griffiths DJ: Editorial: bladder failure--a condition to reckon with. J Urol. 2003; 169(3): 1011-2.

PubMed Abstract | Publisher Full Text

20. Abrams PH, Griffiths DJ: The assessment of prostatic obstruction from urodynamic measurements and from residual urine. Br J Urol. 1979; 51(2): 129-34.

PubMed Abstract | Publisher Full Text

21. Schäfer W, Waterbär F, Langen $\mathrm{PH}$, et al:: A simplified graphic procedure for detailed analysis of detrusor and outlet function during voiding. Neurourol Urodyn. 1989; 8: 405-7. Reference Source

22. Rosario DJ, Woo HH, Chapple CR: Definition of normality of pressure-flow parameters based on observations in asymptomatic men. Neurourol Urodyn 2008; 27(5): 388-94.

PubMed Abstract | Publisher Full Text

23. Schmidt $F$, Shin $P$, Jorgensen $T M$, et al: Urodynamic patterns of normal male micturition: influence of water consumption on urine production and detrusor function. J Urol. 2002; 168(4 Pt 1): 1458-63.

PubMed Abstract | Publisher Full Text

24. Pfisterer $\mathrm{MH}$, Griffiths DJ, Schaefer W, et al:: The effect of age on lower urinary tract function: a study in women. J Am Geriatr Soc. 2006; 54(3): 405-12. PubMed Abstract | Publisher Full Text

25. Griffiths DJ: The mechanics of the urethra and of micturition. Br J Urol. 1973; 45(5): 497-507.

PubMed Abstract | Publisher Full Text

26. Griffiths DJ: Assessment of Detrusor Contraction Strength or Contractility Neurourol Urodyn. 1991; 10(1): 1-18.

Publisher Full Text
27. Lecamwasam HS, Yalla SV, Cravalho EG, et al:: The maximum watts factor as a measure of detrusor contractility independent of outlet resistance. Neurourol Urodyn. 1998; 17(6): 621-35.

PubMed Abstract | Publisher Full Text

28. Schäfer W: Analysis of bladder-outlet function with the linearized passive urethral resistance relation, linPURR, and a disease-specific approach for grading obstruction: from complex to simple. World J Urol. 1995; 13(1) 47-58.

PubMed Abstract | Publisher Full Text

29. F Griffiths D: Detrusor contractility--order out of chaos. Scand J Urol Nephrol Suppl. 2004; 38(215): 93-100.

PubMed Abstract | Publisher Full Text | F1000 Recommendation

30. F Tan TL, Bergmann MA, Griffiths D, et al.: Which stop test is best? Measuring detrusor contractility in older females. J Urol. 2003; 169(3): 1023-7. PubMed Abstract | Publisher Full Text | F1000 Recommendation

31. Sullivan M, Yalla SV: Functional studies to assess bladder contractility. $J$ urol Urogynäkol. 2007; 14(1): 7-10. Reference Source

32. Sullivan MP, DuBeau CE, Resnick NM, et al:: Continuous occlusion test to determine detrusor contractile performance. J Urol. 1995; 154(5): 1834-40. PubMed Abstract | Publisher Full Text

33. F Cucchi A, Quaglini S, Guarnaschelli C, et al:: Urodynamic findings suggesting two-stage development of idiopathic detrusor underactivity in adult men. Urology. 2007; 70(1): 75-9. PubMed Abstract | Publisher Full Text | F1000 Recommendation

34. F Cucchi A, Quaglini S, Rovereto B: Different evolution of voiding function in underactive bladders with and without detrusor overactivity. J Urol. 2010; 183(1): 229-33.

PubMed Abstract | Publisher Full Text | F1000 Recommendation

35. F Cucchi A, Quaglini S, Rovereto B: Development of idiopathic detrusor underactivity in women: from isolated decrease in contraction velocity to obvious impairment of voiding function. Urology. 2008; 71(5): 844-8. PubMed Abstract | Publisher Full Text | F1000 Recommendation

36. Rosario DJ, Chapple CR, Tophill PR, et al.: Urodynamic assessment of the bashful bladder. J Urol. 2000; 163(1): 215-20. PubMed Abstract | Publisher Full Tex

37. F van Koeveringe GA, Rahnama'i MS, Berghmans BC: The additional value of ambulatory urodynamic measurements compared with conventional urodynamic measurements. BJU Int. 2010; 105(4): 508-13. PubMed Abstract | Publisher Full Text | F1000 Recommendation 


\section{Open Peer Review}

\section{Current Peer Review Status:}

\section{Version 1}

Reviewer Report 25 January 2016

https://doi.org/10.5256/f1000research.7915.r12061

(C) 2016 Rosier P. This is an open access peer review report distributed under the terms of the Creative Commons Attribution License, which permits unrestricted use, distribution, and reproduction in any medium, provided the original work is properly cited.

\section{Peter F.W.M Rosier}

Department of Urology, University Medical Center Utrecht, Utrecht, The Netherlands

The short commentary 'The underactive bladder: detection and diagnosis' discusses the topic from the perspective of symptoms, epidemiology, pathogenesis, and diagnostic aspects. The paragraphs on diagnostic aspects are a summary of urodynamic testing, more specifically: pressure-flow analysis. I assume that the words '... are typically associated with...' in the introduction and the words '...typical presentation...' in the signs and symptoms section, refer to the historical beliefs of professionals. The last paragraph of the signs and symptoms section mentions that there is a debate on whether there is a symptom complex associated with detrusor underactivity (the underactive bladder syndrome?). I agree with this statement and careful reading of the working definition cited from reference 2 in the commentary makes it obvious that the working definition of (the) bladder outflow obstruction (syndrome) would be exactly identical, if it was introduced nowadays. The elements of the working definition for UAB (as a signs and symptoms syndrome) are equal to those considered, both currently and traditionally, very relevant in men with benign prostatic enlargement ${ }^{1}$. I conclude that the underactive bladder syndrome as it is suggested here is not specific, like all LUTD-syndromes, and that, indeed, underactive detrusor (contraction during voiding) is a condition only assessable with a pressure-flow study.

There is some observational clinical data on how the detrusor compensates for the growing prostate and the-by consequence-increase in bladder outflow obstruction, in addition to the animal studies referred to in the commentary, to explain the pathophysiology ${ }^{2}$. With the perspective of DU, this clinical study may allow two interpretations; first: the detrusor of aging men increases (maximum) power to compensate for the growing prostate and second: some detrusors are better able to compensate than others. The validity of the clinical observation ${ }^{2}$ was subsequently confirmed in a canine experiment ${ }^{3}$. If relevant neurogenic abnormalities are excluded on the basis of history and clinical examination, myogenic factors remain as the cause of detrusor underactivity, and based on biologic variance, some detrusors will be stronger than others and some will be better able to conquer challenges. The search for relevant amino-acids or other molecules will be important here if we want to discover ways to improve the symptomatically weak detrusors. 
Urodynamic diagnosis of detrusor contraction work or power during voiding is not yet standardized, and the commentary gives a neat overview of parameters that may prove to be useful. Especially objective parameters that will demonstrate predictive value and responsiveness to management will become relevant in the future.

Cooperation with the patient is necessary to obtain a representative pressure-flow test, and the autonomic voiding reflex requires parasympathetic dominance in a-for the patient involved-stressful situation. This is even more important when the patient has a 'bashful bladder'. I consider it valuable that this is introduced here in this context. Based on the relevance of this dysfunction, that will exist in a continuum from 'low grade' to 'very troublesome', the new ICS Good Urodynamic Practices and Terms (that will be available in 2016) will introduce the terms (or diagnoses) 'situational inability to void' and 'situational inability to void as usual'. Whether ambulatory urodynamics provides a reliable method to obtain a pressure-flow test remains speculative however, because of the lack of evidence.

\section{References}

1. Abrams P, Chapple C, Khoury S, Roehrborn C, et al.: Evaluation and treatment of lower urinary tract symptoms in older men.J Urol. 2009; 181 (4): 1779-87 PubMed Abstract | Publisher Full Text 2. Rosier PF, de Wildt MJ, de la Rosette JJ, Debruyne FM, et al.: Analysis of maximum detrusor contraction power in relation to bladder emptying in patients with lower urinary tract symptoms and benign prostatic enlargement.J Urol. 1995; 154 (6): 2137-42 PubMed Abstract 3. Lecamwasam HS, Sullivan MP, Cravalho EG, Yalla SV: Detrusor internal and external work in relation to passive urethral resistance in a canine model of the lower urinary tract.Neurourol Urodyn. 1996; 15 (5): 529-43; discussion 544 PubMed Abstract | <529::AID-NAU9>3.0.CO;2H">Publisher Full Text

Competing Interests: No competing interests were disclosed.

I confirm that I have read this submission and believe that I have an appropriate level of expertise to confirm that it is of an acceptable scientific standard.

Reviewer Report 25 January 2016

https://doi.org/10.5256/f1000research.7915.r12060

(C) 2016 Yoshimura N. This is an open access peer review report distributed under the terms of the Creative Commons Attribution License, which permits unrestricted use, distribution, and reproduction in any medium, provided the original work is properly cited.

\section{Naoki Yoshimura}

Department of Urology, University of Pittsburgh, Pittsburgh, PA, USA

Competing Interests: No competing interests were disclosed.

I confirm that I have read this submission and believe that I have an appropriate level of 
expertise to confirm that it is of an acceptable scientific standard.

The benefits of publishing with F1000Research:

- Your article is published within days, with no editorial bias

- You can publish traditional articles, null/negative results, case reports, data notes and more

- The peer review process is transparent and collaborative

- Your article is indexed in PubMed after passing peer review

- Dedicated customer support at every stage

For pre-submission enquiries, contact research@f1000.com 